\title{
SOBRE MASCULINIDADES, ATIVISMO E ESTUDOS PÓS-COLONIAIS: entrevista com o antropólogo Miguel Vale de Almeida
}

\author{
Carmen Silvia de Moraes Rial* \\ Giovanna Maria Poeta Grazziotin ${ }^{* *}$ \\ Juliana Bez Kroeger ${ }^{* * *}$ \\ Rochelle Cristina dos Santos ${ }^{* * *}$ \\ Cintia Lima Crescêncio ${ }^{* * * *}$
}

O antropólogo social, Miguel Vale de Almeida, é professor no Instituto Universitário de Lisboa (ex-Instituto Superior de Ciências do Trabalho e da Empresa), e pesquisador do Centro em Rede de Investigação em Antropologia (CRIA), onde já dirigiu a linha de investigação “Identidades Sociais e Diferenciações”, bem como a revista "Etnográfica”. O antropólogo realizou estudos em Portugal, Brasil e Espanha sobre os seguintes temas: masculinidades, movimento negro, pós-colonialismo lusófono e casamento entre pessoas do mesmo sexo. Entre as suas publicações acadêmicas, destaca-se a obra 'Senhores de Si: uma interpretação antropológica da masculinidade’, livro que se tornou uma referência nos estudos de gênero sobre masculinidades. Miguel Vale de Almeida tem-se destacado também como um

\footnotetext{
Doutora em Antropologie et Sociologie pela Université de Paris V. Professora do Programa de PósGraduação em Antropologia Social da Universidade Federal de Santa Catarina. E-mail: rial@cfh.ufsc.br

** Mestranda em História pele Universidade do Estado de Santa Catarina. E-mail: giovannapoeta@yahoo.com.br

*** Mestranda em História Cultural na Universidade Federal de Santa Catarina.

**** Mestranda em História pela Universidade do Estado de Santa Catarina. E-mail: rochellecristina@hotmail.com

Mestranda em História pela Universidade Federal de Santa Catarina.
} 
dos principais intelectuais portugueses que atuam no movimento social LGBT (lésbicas, gays, bissexuais, transexuais, travestis e transgêneros). Em 2009, foi eleito deputado da Assembléia da República, o parlamento de Portugal.

Tempo e Argumento: Qual foi a sua trajetória no campo dos estudos de gênero até a construção da obra "Senhores de si"?

Miguel Vale de Almeida: Até o livro “Senhores de si”, a trajetória foi pequena, porque este foi o meu primeiro livro. ${ }^{1}$ Ele foi o resultado da tese de doutorado, não havendo grande percurso intelectual anterior. O que houve, sim, foi o curso de graduação em Antropologia, em Lisboa. O referido curso difere do sistema brasileiro porque nós tínhamos uma graduação em Antropologia de quatro anos. Fiz uma graduação de Antropologia durante quatro anos e, portanto, era um ensino muito aprofundado. Aprendi Antropologia e, depois, fui para os Estados Unidos fazer mestrado durante dois anos. Naquele país, sim, tive um momento de encontro com as questões de gênero, que em Portugal estavam subdesenvolvidas. Era 1984 e, praticamente, não existia nada sobre gênero ou sexualidade na universidade portuguesa. Eu fui para a Universidade Estadual de Nova York estudar Antropologia do Desenvolvimento e Antropologia Econômica, com articulação também com o Centro Fernando Braudel, do Immanuel Wallerstein. Lá, tive uma professora que foi fundamental, a antropóloga Catherine Lutz, que, hoje, é professora na Brown University. Ela era uma pessoa que trabalhava questões relativas às emoções - a Antropologia cognitiva -, etc. Naquele momento, produzi um trabalho sobre homossexualidade para uma disciplina dela. Ela achou o trabalho fantástico. A partir de então, comecei a me interessar por questões de gênero. Quando voltei para Portugal, em 1986, decidi trabalhar no doutorado sobre o tema das masculinidades. Na época, eu achava que aquela área ainda era desenvolvida dentro dos estudos de gênero. Realizei o trabalho de campo entre 1990 e 1991 e, em 1994, defendi a tese de doutorado. O livro “Senhores de si” estreou em 1995. O percurso, nessa época, é esse: de estudante.

\footnotetext{
${ }^{1}$ VALE DE ALMEIDA, Miguel. Senhores de Si. Uma Interpretação Antropológica da Masculinidade. Lisboa: Fim de Século, 1995.
} 
Tempo e Argumento: A repercussão do seu trabalho sobre masculinidades na obra "Senhores de si" foi grande no campo dos estudos de gênero. O professor pode comentar sobre esse processo em Portugal e no Brasil?

Miguel Vale de Almeida: A repercussão inicial foi no Brasil. Isso é muito curioso. Em Portugal também teve repercussão, porém não tanto, porque a preocupação com a área de gênero não estava tão desenvolvida. Eu fiz depois uma edição inglesa do livro, que foi publicada na Inglaterra e nos Estados Unidos, simultaneamente. A obra teve algum sucesso, mas se confrontou com aquele establishment americano e inglês de alguns autores que dominavam a área da masculinidade e nunca dialogaram comigo. Eu creio que é uma questão dos processos de hegemonia acadêmica. Antropólogos (provenientes) de Portugal ou do Brasil “não valem nada”, pois nunca houve diálogo com o meu trabalho. Em Portugal, o livro teve bastante repercussão também pelo fato de eu ser homem e estar trabalhando sobre gênero, uma área que, até então, era relacionada aos estudos de mulheres. Isso ajudou a abrir o campo dos estudos de gênero no país. A partir daí, o campo do gênero, em Portugal, passou a ser não mais especificamente feminino, mas feminino e masculino.

Tempo e Argumento: Quinze anos após a emergência da obra "Senhores de si”, como o professor vê o cenário dos estudos de gênero no campo das masculinidades?

Miguel Vale de Almeida: Atualmente, eu deixei de trabalhar especificamente sobre masculinidades. Eu trabalhei sobre masculinidade hegemônica, pois o meu propósito era explicar o processo através do qual um homem se torna heterossexual, patriarcal, etc. É um processo construído, ou seja, que não era natural. Mas, na realidade, o que eu fiz foi pegar um objeto que para mim era exótico, uma vez que sou um homem homossexual e tenho uma perspectiva crítica sobre o gênero e a sexualidade. A heterossexualidade masculina era estranha para mim, e, portanto, necessitava ser explicada. Esse exercício gerou algum efeito. Grande parte dos estudos sobre masculinidades deixou de ser apenas sobre os homens heterossexuais enquanto parceiros de mulheres heterossexuais e passou a considerar também a heterossexualidade como uma coisa que necessita ser explicada. Hoje em dia eu deixei de estudar a questão da masculinidade hegemônica e passei a trabalhar sobre outros assuntos: orientação sexual e, bastante, sobre questões homossexuais; estas últimas, não enquanto antropólogo, mas enquanto ativista. É uma história bem complexa, pois, enquanto 
antropólogo, eu trabalhei sobre masculinidade heterossexual; enquanto ativista, sobre homossexualidade.

Tempo e Argumento: No Tempo Presente a relação entre a mídia e o saber acadêmico modificou-se profundamente. Qual a sua experiência em relação a esse fenômeno?

Miguel Vale de Almeida: É uma experiência muito má e muito parecida com a relação da mídia com a política. A mídia sofreu transformações muito fortes, deixando de ter a figura do jornalista intelectual, pelo menos na Europa. É um mundo muito complicado. Os jornais e as empresas de televisão são grandes empresas, que funcionam para fazer lucro, inclusive certas televisões do Estado. Os jornalistas deixaram de ser profissionais full time, passando a ser estagiários pagos de forma irregular e sem contrato de trabalho fixo. O que eles fazem é buscar a notícia muito rápida ou telefonar para o acadêmico para fazer uma pergunta idiota, sobre um assunto idiota e sem fazer o "trabalho de casa", de tentar compreender os assuntos. Portanto, a relação entre a mídia e as Ciências Sociais é muito complicada, porque nunca se pode dar uma resposta direta e concreta a um fenômeno, pois o jornalista não tem nem tempo, nem espaço para contextualizar a complexidade dos fenômenos sociais. Às vezes, é interessante apenas no sentido de que nós podemos ajudar a legitimar certas coisas, uma vez que ainda há certo respeito estatutário pelos acadêmicos. É possível legitimar um determinado assunto, sobretudo com aqueles jornalistas mais antigos, que, por sua vez, assumem a defesa de certas causas. Eles falam com os acadêmicos e tentam transformar o seu trabalhoreportagem em uma coisa capaz de influenciar a sociedade, isto é, pegam aquilo que a academia faz e traduzem para uma linguagem jornalística. Mas são muito poucos os jornalistas que fazem isso. A maior parte almeja apenas uma resposta para os eventos do cotidiano, normalmente com respostas já dadas quando a pergunta é feita, ou seja, deseja uma confirmação das suas próprias expectativas enviesadas. Portanto, a relação entre mídia e o saber acadêmico é muito complicada.

Tempo e Argumento: O senhor foi eleito deputado num país de maioria católica para defender bandeiras que contrariam preceitos, muitas vezes fundamentais desse ideário. $O$ senhor poderia comentar sobre essa experiência no campo da cultura política? 
Miguel Vale de Almeida: A primeira coisa que eu creio ser importante neste debate é a questão do catolicismo, que precisa ser relativizada. Todos os jornais anglo-saxônicos e norteamericanos, quando foi aprovado o casamento gay, em Espanha ou, agora, quando foi em Portugal, vinham com a paranóia de sempre: “país católico aceita casamento gay”. Eu escrevi um artigo sobre este tema, que apresentei na Associação Americana de Estudos Portugueses. Os nossos países possuem uma vivência da religião diferente. Portugal, Espanha, ou mesmo a Itália, são aquilo que alguns sociólogos chamam de países pós-católicos, isto é, o catolicismo é a religião que a maior parte das pessoas afirma ter de ponto de vista descritivo-identitário. É a religião em que eu fui educado; é aquela em que eu fui batizado, mas isso não tem nenhuma relação necessária com a prática e a crença no catolicismo. Eu, normalmente, costumo afirmar aos meus colegas anglo-saxônicos que um indicador muito importante é a taxa de frequência dominical da igreja. Este é um indicador utilizado para medir a forma como as pessoas se relacionam com uma religião, tal como a católica. Em Portugal, não chega aos vinte por cento, ou seja, ninguém vai à igreja. Quando há inquéritos sociológicos sobre a autoridade do Papa e da Igreja numa série de questões, você indaga uma maioria esmagadora de autodenominados católicos que, por exemplo, usam a pílula anticoncepcional, a camisinha e que aceitam relações sexuais pré-matrimoniais. Esta maioria é que aceitou a legalização do aborto. Nós tivemos um referendo em Portugal no qual foi aprovada a despenalização do aborto, com setenta por cento dos votos. Então os católicos votaram a favor do aborto. Portanto, a forma sociológica de entender a religião não pode ser automática. $\mathrm{O}$ fato de as pessoas se descreverem como católicas não significa que sejam praticantes, obedientes, etc. Há uma tradição política muito forte em Portugal, que é maior que a do Brasil, relativa à tradição republicana laica, sobretudo depois do fim da ditadura em 1974. A ditadura estava associada à Igreja Católica. Com o fim da ditadura e o processo de democratização, foi muito importante a separação do Estado e da Igreja. Tivemos o reforço da tradição laica republicana da Primeira República de 1910, que tinha sido terminada pela ditadura de Salazar. Em Portugal, há uma tradição popular anti-clerical muito forte, mesmo no campo. As pessoas dizem-se católicas, mas desobedecem à Igreja. Há uma separação muito forte entre o catolicismo, como uma prática privada e da comunidade e a obediência à Igreja. As pessoas autonomamente organizavam as festas, as romarias, as peregrinações etc., e desobedeciam ao padre sistematicamente se este não correspondesse à vontade coletiva. Uma religião dividida no sentido de uma tradição anticlerical contra os padres e contra a égide da Igreja. A grande batalha de gênero e sexualidade em Portugal foi o aborto. Nós tivemos uma revolução em 1974, que constituiu uma ditadura e tivemos um processo revolucionário de esquerda muito 
forte, que depois terminou, transformando-se num processo de democracia liberal, seguido da entrada na União Europeia. Aquilo que nós chamamos normalização, ou seja, uma democracia liberal, em que todos os direitos praticamente foram garantidos: a lei do divórcio, a igualdade plena entre homens e mulheres, leis contra a violência de gênero, etc. Só que faltava a questão do aborto. Essa não se conseguia resolver, pois a hierarquia da Igreja Católica pressionava os governos no sentido de não permitir isso. Houve um primeiro referendo, que surgiu na seqüência de um problema. As coisas em Portugal não se decidiam através de referendo, mas houve uma lei no parlamento para liberalizar o aborto. Esta lei estava praticamente aprovada porque havia uma maioria de esquerda no parlamento. Todavia, na última hora, o Primeiro Ministro, socialista à época, que era católico praticante, fez um acordo com o líder da oposição, que era antiaborto, decidindo convocar um referendo. Estes afirmavam que era um assunto muito importante e não podia ser decidido no parlamento. Esse referendo nós perdemos, porque não foi vinculativo, isto é, pouca gente foi votar. Portanto, o referendo não teve efeito de lei; mesmo assim, ganharam os adversários da despenalização do aborto. Para ser feito outro referendo, foi necessário esperar um período de anos. Houve uma luta muito grande do movimento feminista e da esquerda em geral no sentido de fazer um novo referendo. Finalmente, fizemos o referendo em 2008. Nós mudamos completamente o tom da campanha. Este fato talvez seja importante para as brasileiras e os brasileiros em termos de estratégia. Tivemos de deixar de utilizar um discurso feminista mais radica,l relacionado com o direito da mulher ao corpo. Por outro lado, utilizamos o discurso da igualdade de direitos e da autonomia das pessoas. Ganhamos o referendo com uma maioria esmagadora de votos. Foi uma derrota histórica para a Igreja. Quando teve início o debate da questão do casamento gay (em Portugal), a Igreja não se manifestou, ao contrário da Espanha ou da Argentina. Porque é que nós escolhemos o casamento gay? E quem é o nós? Há vários nós estou falando em movimento social, lésbicas, gays, bissexuais e transgéneros (LGBT), que é muito diverso em Portugal. Há um núcleo central que é mais moderado, do ponto de vista das posições políticas, e que, a partir de 2003, escolheu a questão do casamento gay como a questão central. Nós verificamos o casamento, que o casamento era de fato, como eu chamo no meu livro, a chave do armário. Era aquela mudança legal que permitia todas as outras. Por quê? Por várias razões, que têm a ver com a idéia de reconhecimento. Quando uma sociedade, a lei e o Estado afirmam que duas mulheres ou dois homens podem casar, isto é, podem ascender ao símbolo máximo de reconhecimento da sexualidade e conjugalidade, significa que são iguais aos outros. Portanto, esse lado simbólico do casamento é que nos interessava. Interessava-nos menos a questão dos direitos civis, porque isso já tínhamos. Em 
Portugal, havia uma lei que regulamentava a união civil desde 2001. Eu vivia de acordo com ela e tinha praticamente todos os direitos de um casamento. Então, concentramos a estratégia toda nessa reivindicação: Casamento! Casamento! Casamento! E tanto fizemos que convencemos a sociedade portuguesa, aos poucos, através da mídia. Neste caso, a mídia televisiva foi importante, com grandes programas de debate sobre o assunto. Mas tínhamos um problema político. No espectro político-partidário só a extrema esquerda apoiava a nossa causa. Nós percebemos cedo que não conseguiríamos nunca aprovar o casamento gay apenas com o apoio da extrema esquerda. Precisávamos do apoio do setor central da política, que em Portugal é o Partido Socialista, equivalente ao Partido dos Trabalhadores, no Brasil. Conseguimos fazê-lo através de muito lobby. Finalmente, com esse primeiro ministro do Partido Socialista, eles colocaram a questão do casamento gay no programa eleitoral. O Partido Socialista ganhou as eleições, sendo depois relativamente fácil no parlamento conseguir uma maioria de esquerda que aprovou a lei.

Tempo e Argumento: A emergência dos estudos culturais colocou em cena sob outro paradigma: a relação entre os países europeus e os que foram colônias, entre os séculos 16 e 19. O professor pode comentar sobre este processo histórico, tendo em vista o caso Portugal, Brasil e os países africano?

Miguel Vale de Almeida: Eu pesquisei muito sobre este tema em termos da chamada teoria pós-colonial, mas sempre em relação ao caso português, brasileiro e dos países africanos de língua portuguesa. Colegas brasileiros, portugueses e eu temos trabalhado muito em conjunto; produzimos um livro chamado "Trânsitos Coloniais", que trata sobre essa questão. ${ }^{2}$ Nossos estudos dialogam, mas também fazem oposição à denominada teoria pós-colonial produzida pela academia norte-americana e inglesa. Por quê? Porque achamos que o processo colonial em Portugal foi um processo diferente do inglês e do francês, uma vez que foi constituído a partir de um Estado muito fraco e pobre. Ao mesmo tempo que afirmamos que foi um processo colonial diferente, não procuramos subscrever as idéias do luso-tropicalismo, que são ideologicamente falsas. O grupo tem realizado estudos no sentido de perceber o que é específico no colonialismo português e no pós-colonialismo em língua portuguesa, sem necessariamente aceitar as premissas do luso-tropicalismo, com o qual, como afirmei, não

\footnotetext{
${ }^{2}$ FELDEMAN-BIANCO, Bela; BASTOS, Cristina; VALE DE ALMEIDA, Miguel (Org.). Trânsitos Coloniais: diálogos críticos luso-brasileiros. Campinas: Editora da UNICAMP, 2007.
} 
concordamos. Uma das questões fundamentais na situação pós-colonial em relação à língua portuguesa é perceber que o Brasil não é exatamente uma pós-colônia. É legítimo afirmar que o Brasil ficou independente de Portugal em 1822. Por outro lado, é legítimo afirmar que Portugal ficou independente do Brasil, porque não existia uma relação de poder colonial e de colônia no sentido de um grande país forte, com uma grande economia e um exército forte e uma pequena colônia de povos indígenas colonizados. O que existia era um mundo lusobrasileiro único, em que o Brasil, inclusive, tinha uma força econômica e demográfica enorme. Muitas vezes, era a partir do Rio de Janeiro que a sociedade colonial era gerida. Angola era administrada pelo Brasil e por Portugal, contexto, aliás, historicamente único. Eu acho que nós temos que levá-lo a sério porque eles continuam visíveis hoje em dia. O tipo de relação entre Portugal e Brasil, ou entre Portugal e África, ou, ainda, entre Brasil e a África de língua portuguesa não é o mesmo tipo de relação que a Inglaterra possui com as suas excolônias. Não é porque seja boa, simpática, cordial, luso-tropical, não, é porque é diferente do ponto de vista do contexto histórico, econômico e social que criou o mundo colonial. Esta é uma pesquisa que historiadores e antropólogos estão fazendo continuadamente, ao longo dos anos, no Brasil e em Portugal.

Recebido: Outubro/2010

Aprovado: Novembro/2010 